\title{
The fittingness of emotions
}

\author{
Hichem $\operatorname{Naar}^{1} \mathbb{B}$
}

Received: 30 April 2021 / Accepted: 27 August 2021 / Published online: 20 September 2021

() The Author(s) 2021

\begin{abstract}
We often assess emotions as appropriate or inappropriate depending on certain evaluative aspects of the world. Often using the term 'fittingness' as equivalent to 'appropriateness', many philosophers of emotion take fittingness assessments of emotions to be a broadly representational matter. On this sort of view, an emotion is fitting or appropriate just in case there is a kind of representational match between the emotion and the object, a matching analogous to truth for belief (or veridicality for perception). This view provides an account of the relationship between emotion and value that many have found plausible. In this paper, I argue that the fittingness of emotions should not be understood in representational terms. Rather, as is common in the literature on fittingness, we should interpret the notion in normative terms. After providing four arguments against the representational interpretation, and for a normative interpretation, of emotional fittingness, I discuss two ways to develop the normative picture of emotional fittingness. I also clarify the relevant issues that will have to be tackled by philosophers of emotion in the future, issues which cannot be tackled without attending to action theory and the philosophy of normativity.
\end{abstract}

Keywords Emotion $\cdot$ Fittingness $\cdot$ Appropriateness $\cdot$ Value $\cdot$ Normativity $\cdot$ Reasons

We often assess emotions as appropriate or inappropriate depending on certain evaluative aspects of the world. Sarah's anger at Tom for his remark is appropriate given that the remark was insulting. Marco's admiration for Natalia is appropriate given the life of achievements she has had. And Wasir's fear of the dog is inappropriate given that she does not pose any threat to him. Talk of appropriateness, then, is pervasive. But what do we mean by it? What is it for an emotion to be an appropriate response to some object?

Often using the term 'fittingness' as equivalent to 'appropriateness', many philosophers of emotion take fittingness assessments of emotions to be a broadly representational matter. On this sort of view, an emotion is fitting or appropriate just in case

Hichem Naar

hm.naar@gmail.com

1 Department of Philosophy, University of Duisburg-Essen, Essen, Germany 
there is a kind of matching between the emotion and the object, a matching analogous to truth for belief. Just as a belief is true, or 'correct', just in case the world is as it says it is, an emotion is fitting just in case the world is as it says it is. Just like belief, advocates of the view hold, emotions have a content that can be assessed for correctness, understood as objective matching on the model of truth, and talk of appropriateness/fittingness is simply another way to refer to this form of assessment. This is an assumption we find in Julien Deonna and Fabrice Teroni's influential discussion of the emotions; they write:

First, and as a direct consequence of their being directed at particular objects and connected with types of evaluations, emotions are subject to standards of correctness. If Leonard is afraid of Fido, a friendly and docile dog, we would tell him that the dog poses no danger and would consider his fear inappropriate. Some such standards seem to apply to all the emotions, though perhaps not $(. .$.$) to all affective phenomena. In this respect, emotions are similar to$ many cognitive states such as beliefs and perceptual experiences. All these states have conditions of correctness, i.e. they have a content in the light of which it is possible to assess whether they fit the facts or not (...). The fact that emotions are assessed as correct or incorrect depending on whether or not they fit the facts has prompted philosophers to talk about them as having the mindto-world direction of fit (...). (2012, p. 6).

And Christine Tappolet seems to take appropriateness and correctness to be identical notions when she says:

[E]motions can be assessed in terms of their appropriateness. We are prone to assess our emotions with respect to how they appear to fit evaluative states of affairs. We criticize someone's fear when it bears on something that is not fearsome, such as an innocuous little spider. This practice strongly suggests that we assume that the emotion represents the spider as fearsome. Thus, fear appears to have correctness conditions in much the same way as the visual experience of poppies as blue has correctness conditions. (2016, p. 20).

This yields a picture on which norms of fittingness/appropriateness for emotions are "norms for correct representation" (Na'Aman, forthcoming, 2). ${ }^{1}$ Here's a statement of the view:

Fittingness of Emotions as Correctness (FEC): Emotions' fittingness (or appropriateness) is just a matter of correct representation. The relation between fitting emotions and the world is broadly the same as the relation between true beliefs (and veridical perceptual experiences) and the world.

\footnotetext{
1 See, e.g., Cowan (2016), D’Arms \& Jacobson (2000), Milona (2016), Tappolet (2016). For this view from outside the philosophy of emotion, see also Rosen (2015). Rosen's view is a minority view in the philosophy of fittingness. Cf. Sharadin (2016).
} 
A widespread assumption in the philosophy of emotion, one which I will accept for the purposes of this paper, is that what makes emotions fitting are certain evaluative properties, rather than non-evaluative properties, of their objects: ${ }^{2}$

Values as Fittingness Makers (VFM): Evaluative properties of objects make emotions fitting (or appropriate). ${ }^{3}$

FEC thus can be seen as providing an elucidation of the relation between fitting emotions and the corresponding values that make them fitting, namely a representational link. In a nutshell, emotions represent values, and they are fitting (read: correct) just in case the values are really instantiated. Combining FEC and VFM, we get:

Representational Link (RL): Emotions represent evaluative properties (as instantiated by an object), and are correct just in case these properties are instantiated (where correctness is to be understood by analogy with truth for belief, i.e., representationally). ${ }^{4}$

Given RL, it is natural to think that any notion of a normative reason for, and any other normative assessment of, emotions is going to be a matter external to both fittingness and values. ${ }^{5}$ If fittingness is a representational matter, then any assessment in terms of normative reasons (or any other normative assessment, e.g., in terms of ought) will be distinct from an assessment of its fittingness, just like an assessment in terms of truth for belief is distinct from an assessment in terms of epistemic, moral, prudential, etc. reasons. ${ }^{6}$ After all, it is standard to think that truth and justification are distinct properties a belief can have, such that a belief can be true but lack justification and it can be justified but false. This suggests that whatever makes belief correct — the truth of a proposition, the obtaining of a state of affairs, etc. —is

\footnotetext{
${ }^{2}$ One classic motivation for this claim is that an appeal to independent values is necessary for emotions to be individuated into types (Kenny, 1963). For discussion, see Deonna \& Teroni (2012, p. 41).

3 Notice that VFM conflicts with reductive analyses of value in terms of fittingness. According to them, having value is just a matter of making emotions (and other responses) fitting, such that values are not independent entities making them fitting. Since fittingness in this context is standardly understood as a normative notion, FEC should be rejected by an advocate of fitting attitude analyses of this reductive sort. In the following, I will assume their falsity for the sake of argument.

4 Deonna and Teroni's final account is difficult to fit into the thesis here, as they are keen to deny that emotions have evaluative content. Still, to the extent that they claim that the relationship between emotions and values is broadly epistemic, and thus that correctness should be understood by analogy with truth, I'll leave aside this complication in what follows. The argument in what follows is meant to apply to Deonna and Teroni's view equally well.

5 I am here assuming that representational correctness is a non-normative notion (see, e.g., Tappolet, 2011, see also Howard, 2018, p. 9f). If the reader is unhappy with the assumption, they can interpret the alternative picture to be defended here as claiming that the fittingness of emotions should be understood in normative terms distinct from that of representational correctness.

${ }^{6}$ Given this contrast, it is easy to see why some have taken the moral, prudential, etc. assessments of emotions as of the wrong kind to fix their fittingness (see especially D'Arms \& Jacobson, 2000). Additionally, the contrast makes sense of the common idea that an emotion can be appropriate but nonetheless unjustified: "[emotions] can be unjustified even if, by chance perhaps, they meet the standard of correctness just mentioned. That is the case if, although Bernard's wife is really in good health, his elation is based on the testimony of an unreliable informant." (Deonna \& Teroni, 2012, p. 7).
} 
not going to constitute a normative reason for it, and that whatever makes belief justified-e.g., evidence-is not going to make it correct. The assumption that correctness (hence, assuming FEC, fittingness) and justification are distinct is a claim Deonna and Teroni explicitly endorse when they write ${ }^{7}$ :

[S]tandards of correctness so conceived should be distinguished from epistemological standards by which we assess the justification of emotions. Indeed, emotions are often assessed as justified or unjustified in light of the reasons the subject has for them. (...) In this (...) respect, emotions resemble beliefs, for which we also often reasons (that may or may not justify them), and differ from perceptions that can be said to be correct or incorrect but which are not justified by reasons. (Deonna \& Teroni, 2012, pp. 6-7).

In light of this, we can see that if values are what makes emotions representationally correct, then it is difficult to maintain that they can themselves provide normative reasons for feeling them, ${ }^{8}$ as correctness is here thought to be distinct from justification. $^{9}$

In this paper, I argue against FEC. The notion of the fittingness of emotionsat least the one that has a footing in ordinary thought - should not be modelled on the relation that obtains between beliefs and true propositions. Rather, it should be understood in normative terms, a claim we will see is in line with much of the literature on fittingness. ${ }^{10}$ Given VFM, the way values make emotions fitting will be by standing in a certain normative relation to them, in turn casting doubt on RL. The upshot will be that what theory of emotions we should accept turns on crucial issues in the philosophy of normativity and action theory that no philosopher of emotion should ignore. ${ }^{11}$

Here's the plan of the paper. In Sect. 1, I discuss the motivations for FEC. In Sect. 2, I canvass four arguments for the conclusion that the fittingness of emotions should be conceived in non-representational, normative terms. In Sect. 3, I briefly discuss two ways to develop the normative picture of emotional fittingness, and I

\footnotetext{
7 See also Echeverri (2019).

8 This explains why the only reasons Deonna and Teroni attribute to the emotions seem to be non-evaluative, indeed broadly epistemic: "Bernard has good reasons to be elated if he has just heard from a reliable witness that his wife is in much better health. His reasons would be bad were his elation based on a report from a notoriously unreliable witness.” (Deonna \& Teroni, 2012, p. 7).

9 Additionally, as Moritz Müller has persuasively argued, the suggestion that an attitude can provide the epistemic access to values - a common claim among advocates of FEC - is difficult to make sense of, and potentially incoherent, if values are supposed to be normative reasons for emotions (Müller, 2017, 2019).

${ }^{10}$ In the philosophy of emotion, this is a minority position accepted by, e.g., Müller (2017, 2019) and that I tentatively endorse in Naar (forthcoming).

11 Another consequence is that we no longer have any clear rationale for countenancing the notion of correctness - as understood by advocates of FEC — when engaging in the philosophy of emotion. Indeed, if the main motivation for appealing to correctness is that it helps provide an account of the fittingness of emotions, hence (given VFM) of the relationship between emotions and values, then we lose the motivation if we reject that account. That said, I leave open the possibility of vindicating the notion of emotional correctness, so long as values are no longer thought to make emotions correct.
} 
clarify the relevant issues that will have to be tackled by philosophers of emotion in the future.

\section{Why accept FEC?}

What are the motivations for FEC, the view that emotions' fittingness is, by analogy with truth for belief, a matter of correct representation? We can discern two main ways to get to this conclusion. On the one hand, one might defend a certain theory of emotions which either implies FEC or makes it very natural to hold it. For instance, one might hold the view that emotions are perception-like or belief-like representations of value, implying that emotions can be (like perception and belief) correct or incorrect depending on whether the value they represent is instantiated. ${ }^{12}$ Given the view that value is what makes emotions fitting (VFM), it is in turn natural to identify the correctness of emotions with their fittingness. ${ }^{13}$ One way to challenge FEC, therefore, is to challenge the accounts of emotions that either imply it or make it very natural to hold. ${ }^{14}$

On the other hand, one might try to motivate FEC more directly by attending to the nature of fittingness. An obvious way to go is to hold the view that fittingness is intimately connected to correctness as a matter of general fact, and so the fittingness of emotions should be understood as correctness (understood non-normatively). ${ }^{15}$ Why take the two notions to be identical? An important reason fittingness is often thought to be the same as correctness stems from the idea that both fittingness and correctness are a matter of internal standards applying to responses in virtue of their nature. Conor McHugh and Jonathan Way write ${ }^{16}$ :

The idea of attitudes having internal standards of fittingness or correctness is a familiar one. The most obvious example is belief. Whatever is the best interpretation of the slogan that belief 'aims at truth', this much is plausible: it is in the nature of the attitude of belief to be assessable as correct or incorrect, according to the truth or falsity of the proposition believed. The attitude of

\footnotetext{
12 For perceptual views of emotion, see Cowan (2016), Döring (2007) Milona (2016), Pelser (2014), Roberts (2013), and Tappolet (2016). For views of emotions as evaluative judgments, see Nussbaum (2001) and Solomon (2003). For a view that denies that emotions are either perceptual or judgmental, but that nonetheless assimilates the fittingness of emotions to the correctness of belief, see Deonna \& Teroni (2012).

13 Unless, of course, one takes values to make emotions both correct and fitting, where correctness and fittingness are conceived as distinct properties. But it is unclear what would be the motivations for this view. In particular, if one takes fittingness to be a matter of reasons, one runs into the odd result that the same thing is what makes emotions correct (i.e., accurate) and justified, which in turn would make emotions quite unlike other kinds of responses, including belief.

14 A realistic way to go is to look at the objections opponents of these accounts have raised against them, which are too numerous to be outlined here. For a general argument against all the relevant accounts, see Müller (2019). For a recent argument against the perceptual theory of emotions in particular, see Naar (forthcoming).

15 See McHugh and Way (2016).

16 See also McHugh (2014).
} 
belief thus sets truth as its standard of correctness. We take correctness for belief to be an instance of the broader category of fittingness. (2016, p. 584).

It is difficult to deny that fittingness is associated with some sort of internal standard. Indeed, the claim that a response is fitting or appropriate seems to mean, at least in part, that qua response of a certain kind it is successful in some way. The suggestion may be expressed with the idea that the 'aim' of the attitude is satisfied and thus, just like for belief, in terms of representational correctness (assuming, as is plausible, that the 'aim' of belief is truth). ${ }^{17}$ From this, one might then suggest that a view of emotions as representational can easily accommodate emotions' fittingness, understood as representational correctness, along the same lines as belief (FEC). ${ }^{18}$ And given the claim that evaluative properties of objects make emotions fitting (VFM), we get the conclusion that emotions represent evaluative properties and are (representationally) correct just in case these properties are instantiated (RL).

There is no doubt that there is a notion of fittingness that philosophers employ and that means roughly the same thing as correctness. The crucial question is whether this is the one we should appeal to when discussing the emotions. The question is not merely whether the notion of correctness applies to emotions-maybe it does. And perhaps the metaphor of an 'aim' can successfully be motivated in the case of emotions. We might wonder, however, whether the notion of fittingness that corresponds to our everyday talk of 'appropriateness' is really the one involved in FEC. After all, we don't ordinarily assess emotions in terms of fittingness. Instead, we use expressions such 'appropriate', 'inappropriate', (perhaps to a lesser extent) 'merited', and even 'should' (e.g., 'you shouldn't be afraid'). To the extent that the notion of fittingness should track ordinary normative practice when it comes to the emotions, it is important to ask whether the notion of fittingness as correctness is the one we should employ. This question is all the more important as the conception of the fittingness of emotions as representational correctness, combined with the claim that values are what make emotions fitting (VFM), directly leads to a substantive account of the relationship between emotions and values which have been resisted by some philosophers. ${ }^{19}$ Putting pressure on FEC is thus an important way to argue for an alternative conception of the relationship between emotions and values.

In the following section, I raise doubts about the claim that the fittingness of emotions should be understood as representational correctness (i.e., FEC). Instead, we should adopt an interpretation of it as a normative matter.

\footnotetext{
${ }^{17}$ I am leaving open the possibility of working out various FEC-friendly ways to cash out the idea of a constitutive aim for emotion.

18 Note that this is not a line McHugh and Way are willing to take. Although they take the idea to apply to belief in a straightforward way-as they think that "beliefs are fitting when they correctly represent how things are" (597), they do not wish to commit to the claim that attitudes such as emotions (desires, intentions, etc.) are correct, hence fitting, in the sense of representing their object accurately (and so, contra the advocate of FEC, they do not wish to model emotions on beliefs). Their notion of correctness is broader than that of representational correctness.

19 At least if paired with the claim that the representation involved in emotions provides an epistemic access to values. See Mulligan (2010), Müller (2017, 2019), and Naar (forthcoming).
} 


\section{Against FEC}

In reading the literature on fittingness, one might get the impression that there is a stable notion of fittingness and that people are trying to elucidate it. Fittingness, however, functions in practice very much like a term of art, despite its presence in the English language. It won't do, therefore, to say that since 'fitting' means 'correct' in some philosophers' talk, ${ }^{20}$ emotions can be correct or incorrect the same way belief can be. For the term 'fitting' means something else in some other philosophers' talk. It is common, for instance, to construe fittingness as a normative notion having to do with normative reasons ${ }^{21}$ or as a sui generis normative relation. ${ }^{22}$

Rather than asking who might have the 'best' conception of fittingness, a more productive way to go is to ask what notion of fittingness best covers the phenomenon at issue. Should we understand the notion of fittingness that, as theorists, we apply to emotions, in terms of representational correctness or should we construe it in other, perhaps normative terms (e.g., in terms of normative reasons)? I think that so long as the notion of fittingness we employ is supposed to capture commonsense thinking about emotions, we should construe it in normative rather than representational terms. ${ }^{23}$ In this section, I spell out four arguments which provide a good cumulative case for denying FEC and accepting an alternative, normative conception of emotional fittingness. The burden of proof will then be on the advocate of FEC to show us wrong. ${ }^{24}$

\subsection{Argument from the naturalness of a normative interpretation}

The first argument directly insists on the sheer naturalness of a non-representational, normative understanding of emotional fittingness. As noted at the outset, the semitechnical notion of fittingness corresponds to the everyday notion of appropriateness. We customarily assess emotions as appropriate or inappropriate. Other notions we deploy to do the same thing are those of merit and worth. ${ }^{25}$ We say that someone does not merit one's love, that they are not worthy of one's love. Although the notion of merit might be cast aside as being dangerously close to that of desert, it is clear that the notion of worth-being worthy of an emotion-is a normative notion.

\footnotetext{
${ }^{20}$ I have been assuming that correctness is a matter of some sort of objective representational match (at least in the case of belief and other representational states). But even this interpretation of the notion is not universal. Some will take correctness to be identical to appropriateness/fittingness, understood as a normative (rather than representational) notion.

21 Howard (2018, p. 3).

22 Maguire (2018).

23 To repeat, I am under no illusion that there is a notion of fittingness as representational correctness in the literature. I won't argue that people are wrong to understand the notion the way they do. What I care about is the notion we are after when we make judgments of appropriateness, and so the one we need when we engage in emotion theory.

24 Notice that it won't do for the opponent to simply insist that FEC is implied by their favorite account of emotions. For the argument in the text is by extension an argument against any view that commits itself to FEC.

${ }^{25}$ We also tend to say that an emotion can be a proper response to its object (Müller, 2017, p. 301).
} 
Saying that someone is worthy of admiration is to claim, at least in part, that admiration is supported by certain considerations: the person's actions speak in favor of admiration. And speaking in favor is a relation that looks quite distinct from that of correct representation. ${ }^{26}$ After all, a true proposition by itself does not speak in favor of a belief; evidence of its truth does. ${ }^{27}$

On top of this, it is worth noting that the view that fittingness is intimately connected to reasons is close to orthodoxy in the philosophy of normativity, where the notion of fittingness is often introduced alongside those of appropriateness, worth, and merit. The following minimal claim about fittingness is accepted by many philosophers $^{28}$ :

Minimal: If A makes $\mathrm{R}$ fitting, then A provides a normative reason for $\mathrm{R}$.

Notice that Minimal does not purport to analyze fittingness in terms of reasons. All it does is point to a relation of entailment between fittingness claims and claims about normative reasons. It is thus compatible with a variety of views, including views that analyze fittingness in terms of reasons and views that take fittingness to be the more fundamental notion in terms of which reasons are analyzed. Notice, however, that Minimal already clashes with the claim that the fittingness of emotions is a matter of correct representation. For reasons mentioned above, it is fair to assume that the fact that a state correctly represents a state of affairs does not entail that that very state of affairs provides a normative reason for the state. This seems true of belief, whereby a true proposition-independently of the presence of evidence for its truth-does not seem to favor belief in it. ${ }^{29}$ But it is even more obvious for perception, where the idea of a normative reason does not even apply. ${ }^{30}$

The fact that there is a rich web of normative notions to which appropriateness and fittingness seem to belong, and that FEC conflicts with a widespread minimal assumption about fittingness, provides a strong prima facie reason to adopt a

\footnotetext{
${ }^{26}$ Even if she accepts FEC, Tappolet sometimes uses the sort of normative language we ordinarily apply to emotions: "My fear can be appropriate or not, depending on whether what I am afraid of is fearsome, that is, depending on whether it calls for fear." (2016, p. 11, my emphasis) If I am right, this sort of talk-innocuous-looking as it might be-is in fact in direct tension with FEC.

27 At least for truths that are not a priori (whose mere contemplation might by itself require belief). But since we are here concerned with contingent instantiations of evaluative properties, this possibility is irrelevant.

28 Howard (2018, p. 3).

29 At least this is a widespread assumption in epistemology, where reasons for belief in a proposition are rarely if ever seen to include the proposition's truth itself. Of course, there are linguistic contexts where the appeal to truth seems to have justificatory force, as when one answers the question 'Why do you believe p?' with 'Because it's true'. Using terminology introduced below, perhaps truth is an 'objective' reason for belief. Although this claim might be satisfactorily defended, this move would not be of much help to the advocate of FEC. Indeed, as we have seen, the relation between emotions and their fittingness makers they appeal to is supposed to be one both belief and perception have with their object. And so since there is no clear sense to be made of the claim that what makes a perceptual experience veridicalhence correct-is a normative reason for it, the notion of representational correctness the advocate of FEC is committed to is incompatible with Minimal. Thanks to a reviewer for raising the issue.

30 Benbaji (2013), Brady (2010), Helm (2001).
} 
non-representational, normative interpretation of emotional fittingness. ${ }^{31}$ Even if emotions might be the sort of thing to be representationally correct, our interpretation of fittingness - the one that corresponds to ordinary talk of appropriatenessmight best be made in non-representational terms. If this is right, then we should reject FEC and any view (such as RL) based on it.

\subsection{Argument from additional mistake}

According to the advocate of FEC, calling an emotion inappropriate is just another way of saying that it is representationally incorrect. It is like calling a belief false and a perceptual experience non-veridical. But it is not. In calling an emotion inappropriate, we do not claim that it is representationally incorrect. Rather, we point to a mistake made over and above that of representing the object incorrectly. As Sigrun Svavarsdóttir writes: "[T]he crucial mistake of those who value an object of no value is hardly that of representing the object falsely." (Svavarsdóttir, 2014).

Consider fear. In claiming that my fear is inappropriate because the object of my fear does not constitute a threat, we are not simply complaining about my inaccurate representation of the object; we are evaluating my fearing the object on top of my misrepresenting it. Intuitively, indeed, it is one thing to take a situation to pose a threat, another to be afraid of it. In a case where I feel fear under the false impression that there is a threat, I seem to be making two mistakes rather than one: I misrepresent my situation and $\mathrm{I}$ feel an emotion that is not appropriate to it. Or so it is very natural to say.ù

The advocate of FEC would have to hold that, in the cases at issue, claiming that I misrepresent my situation would serve virtually the same function as claiming that my fear is inappropriate. This is implausible, however, for two reasons. First, claiming that I misrepresent my situation (just as claiming that I am under an illusion) does not have the flavor of criticism that attaches to judgments of inappropriateness. If the fittingness of emotions was simply a matter of correct representation, then it would be difficult to make sense of the idea that talk of appropriateness and inappropriateness appears to be in the same sort of business as other normative talk such as justification (and, perhaps more controversially, rationality), namely praise and criticism (broadly construed). Indeed, in making the bare claim that one's belief is true, we do not seem to praise one for having come to one's attitude. Neither are we criticizing one in any straightforward way in judging that one's belief is false. At any rate, claiming that one's belief is true/false does not have the sort of flavor enjoyed by the judgment that the belief is justified/unjustified. In fact, the judgment that one's belief is true/false looks a lot like the judgment that one's perceptual experience is veridical/non-veridical: it points to a (mis)match between the world

\footnotetext{
31 To this, we can add that ordinary thinking does not seem to assess emotions as representationally correct (as opposed to presupposing correct or incorrect representations) in the first place, an observation that goes against the common tendency to take this sort of 'epistemic' assessment of emotions (as having a so-called mind-to-world of fit) as a pretheoretical piece of data to be accommodated by an adequate theory (e.g., Deonna \& Teroni, 2012, p. 7).
} 
and one's mental state in a way that does not necessarily involve any sort of (dis) approval of the individual for being in the relevant state.

Second, emotions seem to follow a pattern we find across responses. It is one thing to claim that my desire for a saucer of mud involves a misconception of its value, another to claim that it is inappropriate. Indeed, it is easy to see that I can make the first mistake while avoiding the second: by misrepresenting the value of the saucer of mud while failing to desire it. The same seems true of action: it is one thing to misrepresent the value of foreigners, another to act in a way that corresponds to our take on their value. The mistake of the person who mistreats foreigners is not simply that they see them as bad in some way; the latter mistake was already made before they even started to act. Inappropriate emotions seem to be analogous in involving a mistake that goes beyond that of sheer misrepresentation.

Now, one might wonder what kind of mistake is signaled by talk of inappropriateness. It is plausible that the mistake is a normative mistake. If we take the analogy with other types of responses at face value, and recruit the considerations from the previous argument, we can maintain that, in feeling admiration for a non-admirable person, we are failing to respond to considerations that speak against admiration. This claim is supported by the analogy with other responses. In desiring the saucer of mud, we are not only misrepresenting its value, we are not responding the way we should. The same thing can be said about action: in mistreating foreigners, we are not just misrepresenting their value, we are acting in way that is not supported by it. The claim is also supported by the considerations in the previous argument. Since it is very natural to take appropriateness to be a normative notion, the suggestion that the non-representational mistake made in inappropriate emotions is a normative mistake is highly plausible.

\subsection{Argument from parallel distinctions (and debates)}

In the previous argument, I have assumed an interpretation of appropriateness as a matter of the obtaining of an objective relation between emotions and values, an assumption shared by the advocate of FEC. Instead of claiming that an inappropriate emotion is a matter of an objective representational mismatch-and so a relation that is not affected by facts about the agent's evidence-we should claim that an inappropriate emotion is a matter of an objective mismatch between emotions and the considerations that support them (and so a relation that holds regardless of the agent's evidence or epistemic perspective more generally). We should claim this at least assuming that facts about an agent's epistemic perspective cannot affect the appropriateness of their emotions in some sense. But this assumption can be questioned. Consider admiration at an objectively non-admirable individual. Suppose that one has overwhelming but misleading evidence that the individual is admirable. In a sense, one's admiration might be said to be appropriate: given one's epistemic perspective, one's emotion 'makes sense', and there is no reason against expressing this idea in ordinary language by calling the emotion appropriate, albeit in a way that makes it clear that we are assessing it from the perspective of the agent. 
Although objectively inappropriate, we might say, the emotion is appropriate from one's perspective or subjectively.

Another distinction we might draw is motivated by cases whereby a given individual is genuinely admirable, one has no particular reason to think that they are (the evidence of their admirability is insufficient), but one nonetheless is admirative. In a case like this, it is tempting to say that one's admiration is both appropriate in some sense and inappropriate in some sense. It is appropriate in the sense that the object of one's admiration is genuinely admirable. It is inappropriate in the sense that, from one's perspective, there are no considerations supporting being admirative. Whatever considerations support admiration here are not considerations one possesses, explaining why we might be uneasy with the claim that the emotion is perfectly appropriate. From the agent's perspective, admiration is inappropriate in a straightforward sense. A second distinction, therefore, is between possessed and unpossessed considerations supporting an emotion. Whereas there are considerations supporting admiration in the case at issue, these considerations are not possessed by the agent, where possession is a matter of enjoying some sort of epistemic contact with the relevant considerations. In other words, the considerations are only present in an unpossessed form.

Now, I am not claiming that we should commit ourselves to the subjective/objective appropriateness and possessed/unpossessed considerations of appropriateness distinctions, nor am I in the business of explaining these distinctions further, and how they relate to each other. All I am claiming is that these distinctions are natural distinctions to draw when considering various cases. This should already cast doubt on FEC, as these distinctions are not distinctions we are tempted to give when assessing attitudes as representationally correct or incorrect. There is no clear sense to be made of the thought that, although a belief is objectively true, it is subjectively false. And I cannot think of a non-convoluted way to apply the possessed/unpossessed distinction to truth.

Now, the crucial point: these distinctions can be drawn with respect to the obviously normative notion of justification (and the corresponding notion of a normative reason), and parallel debates can arise with respect to both justification and appropriateness. First, it has appeared to many that a distinction between subjective (or 'apparent') and objective reasons (and a corresponding distinction, for attitudes and actions, between being subjectively justified and being objectively justified) should be drawn. ${ }^{32}$ Consider a case where one has overwhelming but misleading evidence that someone is stealing from one. One reacts by calling the police. Since it turns out that the individual was not stealing, there was no reason to call the police; calling the police was in a sense unjustified. Still, given one's perspective, it is very tempting to say that one had good reason to call the police, since one thought, justifiably so, that one was being robbed. There is a sense in which calling the police was perfectly justified, albeit in a way that makes it clear that our assessment is done by reference to the perspective of the agent. We can then say that, although the action was

\footnotetext{
32 E.g., Schroeder (2008).
} 
objectively unjustified (there were no objective reasons to do it), it was subjectively justified (from the perspective of the agent, there were good reasons to do it).

It has also appeared to many that a distinction between possessed and unpossessed reasons (and a corresponding distinction at the level of attitudes and actions) should be drawn. ${ }^{33}$ Consider again the robber case but with these two modifications: (1) one possesses insufficient (but non-misleading) evidence for thinking that the individual is stealing from them but still call the police (due to prejudice, say); (2) the individual is really stealing from one. There is a sense in which the action of calling the police is justified, given that the individual is really stealing from one. At the same time, it is clear that, since one's reasons for calling the police were insufficient, calling the police was unjustified from their perspective. We can say that though there were reasons for calling the police, one did not possess (enough of) such reasons - the latter were unavailable to one, thereby supporting the claim that the action was in a sense unjustified. ${ }^{34}$

To be sure, we can debate about the nature and philosophical legitimacy of these distinctions, and how they relate to each other. ${ }^{35}$ The point is that they are natural distinctions to draw when considering various kinds of cases. Now, the fact that parallel distinctions can be drawn in appropriateness and justification, and that similar theoretical debates can be had about them, is striking. These similarities call for an explanation. As we have seen, nothing like the relevant distinctions can apply to appropriateness if construed as a matter of representational correctness, and so no corresponding theoretical debates can be had if appropriateness is construed in this way. Of course, that similar distinctions can hold for appropriateness and justification (and that similar debates can be had about both notions) does not entail that they are identical notions. This is a question I will leave open. It is very plausible, however, that the fact that parallel distinctions apply (and the corresponding debates can be had) is due to appropriateness and justification being both normative notions. So, if the notion of fittingness is to have a footing in ordinary thinking about appropriateness, we should reject FEC and adopt a normative interpretation of the notion.

\subsection{Argument from non-representational responses}

Perhaps the most obvious reason for thinking that the notion of appropriateness that applies to emotions (the notion many philosophers are after when employing the

\footnotetext{
33 See, e.g., Lord (2018).

34 See Kiesewetter (2017) for the notion of availability.

35 Further distinctions might be possible. One might distinguish between ex ante appropriateness and ex post appropriateness by analogy with propositional and doxastic justification. See Lord (2018) for the ex ante/ex post distinction. For arguments that only reasons that are within one's epistemic perspective ('possessed', 'available' reasons) are genuine, see, e.g., Kiesewetter (2017) and Gibbons (2010). If these arguments are on the right track, there is no particular reason to doubt that they might extend to appropriateness.
} 
term 'fittingness') is that that very notion seems to apply to non-representational entities. ${ }^{36}$ Action can be appropriate, just as it can be called for or merited. And things can be worthy of certain actions-one can be worthy of punishment, for instance. ${ }^{37}$ Since a response need not even be representational to be subject to conditions of appropriateness, the notion of appropriateness we ordinarily deploy to assess responses is not a matter of correct representation in any straightforward way.

This point is further supported by noting that the way emotions relate to the values that make them appropriate seems to be something that can obtain between actions and values. To see it, notice that to each emotion type conceptually corresponds a set of specific actions-call them the action-counterparts of emotions. ${ }^{38}$ The action-counterparts of anger, for instance, include retaliation, punishment, insult, avoidance, and the like, while the action-counterparts of admiration include emulation, preservation, exploration, promotion, and the like. It is plausible, furthermore, that the action-counterparts of emotion types can be made appropriate by the same evaluative properties as these emotions. Anger and retaliation can be made appropriate by the offensive character of a remark, and admiration and emulation can be made appropriate by the greatness of someone's achievement. There is a question as to whether an emotion's appropriateness implies that at least one of its action-counterparts is appropriate as well. ${ }^{39}$ What matters, though, is that whenever an emotion and one of its action-counterparts are both appropriate, it is very plausible that they relate to the relevant evaluative properties in exactly the same way. Talk of appropriateness, indeed, seems to be uniform across emotions and their action-counterparts. ${ }^{40}$ And so, given that it is implausible that the actions' relation

\footnotetext{
${ }^{36}$ Müller makes a similar point in his $(2014$, p. $75 f)$. For a sustained analogy between emotions and actions, see Naar (forthcoming).

${ }^{37}$ One would then be punishable. The fact that 'punishable' behaves like 'admirable' is a strong reason to think that whatever relation that obtains between an emotion and evaluative aspects of the world should be such as to also obtain between an action and evaluative aspects of the world. For the claim that action might be unduly neglected in the philosophy of fittingness, see Howard (2018, p. 9f).

${ }^{38}$ Church (1995).

39 There is also the question whether the emotions necessarily dispose one to perform their action-counterparts. The discussion in the text is compatible with a rejection of that claim.

${ }^{40}$ Naar (forthcoming). One might suggest that action-counterparts can be appropriate or inappropriate in virtue of the fact that they plausibly count as expressions of emotions. The advocate of FEC could then maintain that action-counterparts are to emotions what assertion is to belief, such that both their elucidation and the elucidation of their appropriateness conditions will make reference to the relevant emotions' representational aspect. (Thanks to Wooram Lee for raising this possibility.) Although intriguing, this option would need proper motivation and development to be fully assessable. Let me note two initial problems with the suggestion as it stands. First, although it can be agreed that action-counterparts can constitute expressions of emotion, they need not. They can be specified independently of the emotions they might express. Slapping certainly can occur in the absence of anger and does not need to be elucidated by reference to anger; slapping need not be an action performed out of anger. In this respect, slapping contrasts with frowning (as when one has an angry face) which more plausibly counts as a direct expression of anger. The fact that action-counterparts are independent from emotions in this way casts doubt on the claim that an adequate conception of their appropriateness should make reference to emotions. Second, even if the relationship between emotions and their action-counterparts was necessarily expressive (one could maintain, not too implausibly, that an action-counterpart that does not actually originate in emotion is still expressive of emotion), it is far from clear that they can be analogized to assertion in any straightforward way. Slapping, running away, and emulating certainly do not look like the mere expression of a representational state or just a matter of performing a communicative act. If
} 
to value is a simple matter of representation, we should find plausible the claim that emotions' relation to value is a non-representational matter. If this is right, then the appropriateness, hence fittingness, of emotions is not a matter of representational correctness. FEC should be rejected.

\section{Fittingness as normative}

The thesis that emotions' fittingness is a matter of correct representation (or more generally a matter of objective match analogous to truth for belief) ${ }^{41}$ is common currency in the philosophy of emotion. I have argued that this thesis should be rejected. The reasons I have given are fairly elementary and not motivated by some underlying theory of emotions. Indeed, the strategy has been to go from general considerations about appropriateness/fittingness to the rejection of FEC. The resulting picture of emotional fittingness is the following:

Fittingness of Emotions as Normative (FEN): Emotions' fittingness (or appropriateness) is a normative matter. The relation of fittingness between emotions and their objects is a normative relation over and above the relation of representation.

Beyond casting doubt on a dogma of contemporary philosophy of emotion, the arguments against FEC, and for FEN, have drastic implications for our account of the relationship between emotions and values. As we have seen, evaluative aspects of objects are generally thought to make emotions fitting (VFM). This claim, combined with FEC, gave us the claim that emotions represent evaluative properties, and are correct (understood representationally) just in case these properties are instantiated (RL). Now, if emotions' fittingness is not a matter of correct representation, but rather a normative matter, then-given VFM - values will make emotions fitting in a normative rather than representational sense.

One might wonder, however, in what sense the fittingness of emotions should be seen as a normative matter. Saying that fittingness is a normative notion, indeed, would probably be seen by many-especially outside the philosophy of emotionas obvious from the outset. A natural move at this stage is to come back to a standard claim in the philosophy of normativity:

Minimal: If A makes $\mathrm{R}$ fitting, then A provides a normative reason for $\mathrm{R}$.

Minimal should look quite plausible in light of some of the foregoing arguments against FEC. It is plausible, indeed, that the reason why we deem admiring an independently admirable person on the basis of inadequate evidence inappropriate is

\footnotetext{
Footnote 40 (continued)

they are appropriate/inappropriate, therefore, this won't be (only) because they presuppose some kind of representation.

${ }^{41}$ For an acceptance of the latter claim combined with a rejection of the claim that emotions literally represent values, see Deonna \& Teroni (2012).
} 
that, from one's perspective, there is no (sufficient) reason to be admirative. ${ }^{42}$ This is why, just like talk of 'unjustified', talk of 'inappropriate' implies some form of personal criticism in cases of this sort. ${ }^{43}$ Furthermore, in cases that involve a non-representational mistake, it is very tempting to claim that an emotion is inappropriate in part because there is no (objective or merely possessed) reason for the individual to feel the way they do. Minimal, therefore, looks like a claim we should be willing to take on board once we are no longer in the grip of FEC. This move is all the more reasonable given that it is compatible with a variety of accounts about the precise way fittingness and normative reasons relate.

Despite its minimal character, Minimal leads to an interesting, albeit controversial, picture of emotional fittingness when paired with the widespread claim that values make emotions fitting (VFM), namely an account according to which evaluative properties themselves provide normative reasons for emotions ${ }^{44}$ :

Values as Normative Reasons (VNR): Values are normative reasons for the emotions they make fitting.

This, of course, is in direct tension with the so-called buck-passing account of value, championed by Tim Scanlon (1998), ${ }^{45}$ according to which values do not provide normative reasons over and above the natural properties on which they supervene. ${ }^{46}$ Granted, the view that values can be normative reasons is quite commonsensical. As Francesco Orsi writes, "[w]e often mean to justify our choices, preferences, or attitudes by simply appealing to the goodness or betterness of an action, or the badness of the alternatives, and so on." (Orsi, 2015, 138-139) Although this view is supported by commonsense, and has historical precedents — notably in Ross (1939)—it might still be seen as going against an important trend in the philosophy of normativity to see value as in need of further elucidation.

\footnotetext{
42 Alternative ways to put the point include that one fails to possess the relevant reasons (e.g., Lord, 2018) and that no reasons are available to one (Kiesewetter, 2017).

${ }^{43}$ For an argument for the claim that personal criticism is a matter of the violation of normative reasons, see Kiesewetter (2017, p. 25).

${ }^{44}$ See Mulligan (2010) and Müller $(2017,2019)$. I flirt with this idea in Naar (forthcoming). Notice that this claim is seen as default in the related literature on reasons for love; if there are reasons for love, most people in the debate think, they will be provided by some evaluative aspect or other of the object.

${ }^{45}$ For an excellent extended defense of the buck-passing account of value, see Rowland (2019). One might wonder whether VNR is compatible with buck-passing accounts of properties such as the admirable, the fearsome, and the disgusting. It is if these properties are not the ones that make emotions fitting. All VNR says is that some evaluative properties provide normative reasons for emotions, which is incompatible with a buck-passing account of these properties. But a buck-passing account of other evaluative properties —notably those that seem to wear emotions on their sleeves (e.g., the admirable) - might still be held. There is reason, however, to claim that these properties are not in fact evaluative, but deontic, especially if we are independently committed to the existence of irreducible value (Müller, 2020; Mulligan, 2010). In line with VNR, one could then maintain that it is not properties such as the admirable that provide reasons for emotions, but those irreducible evaluative properties that make people, e.g., admirable. That said, a full defense of VNR (which would presumably involve a treatment of arguments for the buck-passing account of value) is beyond the scope of this paper.

${ }^{46}$ See also so-called fitting attitude analyses, which elucidate values in terms of fittingness, understood standardly as a normative notion (though see McHugh \& Way, 2016).
} 
Assessing the merits of VNR would take too far afield ${ }^{47}$ Notice, however, that the view has a clear advantage over FEC in that it commits itself to the right sort of account of the fittingness of emotions as a normative matter (FEN). Indeed, VNR follows from two plausible theses: VFM (widely accepted in the debate over the nature of emotions) and Minimal (widespread in the philosophy of normativity and enjoying some initial degree of plausibility).

Now, one might complain that, by contrast with the more general FEN, no sustained argument was given for VFM and Minimal. Instead, VFM was accepted for the purposes of the discussion and Minimal was mainly motivated by an appeal to authority. ${ }^{48}$ This is true. If one is uneasy about VNR, one is free to reject either VFM or Minimal. First, one could reject VFM as unfounded. This, however, would not help the advocate of FEC avoid the arguments given above, for they can easily be formulated without a reference to values. These arguments, indeed, are primarily meant to show that, whatever makes emotions fitting, the relation of fittingness at play between emotions and their fittingness-makers will be normative rather than representational. A rejection of VFM does not mean a rejection of FEN, therefore, which is the immediate conclusion of the arguments above. Given Minimal, we would then be able to claim that whatever makes emotions fitting constitute normative reasons for them.

A rejection of VFM is unlikely to be endorsed by many philosophers of emotion. ${ }^{49}$ Alternatively, one might decide to reject Minimal. According to Barry Maguire, for instance, the relation of normative support between emotions and their objects is crucially different from that between other kinds of responses, including actions, and the world (Maguire, 2018). According to him, the reason relation is a distinct relation from the fit-making relation such that what philosophers often call 'reasons of the right kind'-namely those considerations that make responses fitting (or fittingness-makers) — aren't in fact genuine normative reasons. Just as in the case of VFM, however, a rejection of Minimal (and VNR) does not mean a rejection of FEN, and a vindication of FEC. Maguire's argument, indeed, would not be of much help to the advocate of FEC at this stage, for two reasons. First, Maguire's aim is not to establish anything like FEC. Rather, it is to show that the fittingness of emotions is a normative matter distinct from that of reasons. Arguably, then, he accepts FEN but rejects Minimal. Second, even if Maguire's argument was neutral between FEC and FEN, I have given arguments for rejecting the former and accepting the latter.

\footnotetext{
$\overline{47}$ For an extended argument from critical practice, see Müller (2017). It should be noted that a clear advantage of VNR over the buck-passing account is that it automatically avoids the wrong kind of reason problem that faces the latter. Since values can be appealed to as independent reasons, any reason unrelated to such values (e.g., reasons provided by incentives to form the attitude) will be of the wrong kind to make the relevant emotion fitting. Of course, there remains the question of why, on the view under discussion, certain values are the right kind of reasons (i.e., those reasons that make emotions fitting), that is, what makes them special in comparison to the wrong kind of reasons. This sort of question has received a lot of attention in recent years. For a recent survey, see Gertken \& Kiesewetter (2017).

48 Though it should be clear that those who accept Minimal take themselves to have independent reasons to accept it.

49 One important reason is that values that are specified relatively independently of emotions are standardly thought to be necessary for the individuation of emotions into types.
} 
Rejecting Minimal, therefore, does not commit us to rejecting FEN. This is dialectically important, for this shows that the advocate of FEC cannot rest content with holding a skepticism about normative reasons for emotions in response to arguments against their view. ${ }^{50}$ In making a detour to the highly plausible FEN, the overall argument of this paper thus has a dialectical advantage over arguments that directly appeal to normative reasons for emotions. ${ }^{51}$

\section{Conclusion}

In the course of arguing against FEC, I have suggested that the normative profile of emotions and some actions (i.e., the action-counterparts of emotions) can in fact be examined in parallel in productive and illuminating ways. The picture immediately favored by this analogy is one according to which the fittingness of emotions is a matter of the obtaining of a normative relation (FEN), a claim which contrasts with the view-widely accepted within the philosophy of emotion (but less so outside it) - that the fittingness of emotions is a matter of correct representation. We have seen, furthermore, that a natural way to develop FEN is to accept the minimal, but plausible claim that fittingness entails normative reasons (i.e., Minimal). Combined with the common assumption that values make emotions fitting (VFM), this in turn yields an intuitively plausible, but somewhat controversial account of values as normative reasons for emotions (VNR). I have briefly discussed two ways to resist this account-by rejecting VFM and by rejecting Minimal—none of which would help secure FEC in the face of the cumulative case I have given against it. Although the positive part of the paper was mainly exploratory, I hope it has managed to clarify some crucial issues that philosophers of emotion should attend to more explicitly. If I am right, the philosophy of emotion cannot proceed in isolation from both the philosophy of normativity and action theory. ${ }^{52}$

Funding Open Access funding enabled and organized by Projekt DEAL.

Open Access This article is licensed under a Creative Commons Attribution 4.0 International License, which permits use, sharing, adaptation, distribution and reproduction in any medium or format, as long as you give appropriate credit to the original author(s) and the source, provide a link to the Creative Commons licence, and indicate if changes were made. The images or other third party material in this article are included in the article's Creative Commons licence, unless indicated otherwise in a credit line to the material. If material is not included in the article's Creative Commons licence and your intended use is not permitted by statutory regulation or exceeds the permitted use, you will need to obtain permission directly from the copyright holder. To view a copy of this licence, visit http://creativecommons.org/licen ses/by/4.0/.

\footnotetext{
${ }^{50}$ For a critical discussion of some possible arguments for such skepticism, see Naar (ms.).

51 That said, Maguire's argument has been forcefully criticized. See Faraci (2020).

52 Many thanks to Moritz Bütefür, Wooram Lee, Stefan Mandl, Moritz Müller, Neil Roughley, Katharina Sodoma, Astrid Schomäcker, Christiana Werner for comments on a previous draft of this paper. I also would like to thank Julien Deonna, Michele Palmira, Mauro Rossi, Christine Tappolet, Fabrice Teroni, and an audience at the University of Duisburg-Essen for relevant discussion. This paper is part of the project "The Agency in Emotion" (project number: 422216360), generously supported by the German Research Foundation (DFG).
} 


\section{References}

Benbaji, H. (2013). How is recalcitrant emotion possible? Australasian Journal of Philosophy, 91(3), $577-599$.

Brady, M. S. (2010). Virtue, emotion, and virtue. Metaphilosophy, 40, 115-131.

Church, J. (1995). "L'émotion et l'internalisation des actions", in Paperman, P. \& Ogien, R. (eds.), La couleur des pensées, Raisons Pratiques no.6, Éditions de l'EHESS (pp. 219-236).

Cowan, R. (2016). Epistemic perceptualism and neo-sentimentalist objections. Canadian Journal of Philosophy, 46(1), 59-81.

D’Arms, J., \& Jacobson, D. (2000). The Moralistic Fallacy: On the 'Appropriateness' of Emotions. Philosophy and Phenomenological Research, 61(1), 65-90.

Deonna, J. A., \& Teroni, F. (2012). The emotions: A philosophical introduction. Routledge.

Döring, S. A. (2007). Seeing what to do: Affective perception and rational motivation. Dialectica, 61(3), 363-394.

Gertken \& Kiesewetter. (2017). The right and the wrong kind of reasons. Philosophy Compass, 12, 5.

Gibbons, J. (2010). Things that make things reasonable. Philosophy and Phenomenological Research, 81(2), 335-361.

Helm, B. (2001). Emotional reason: Deliberation, motivation, and the nature of value. Cambridge University Press.

Howard, C. (2018). Fittingness. Philosophy Compass, 13, 11.

Echeverri, S. (2019). Emotional justification. Philosophy and Phenomenological Research, 98(3), 541-566.

Kenny, A. (1963). Action, emotion and will. Routledge \& Kegan Paul.

Kiesewetter, B. (2017). The normativity of rationality. Oxford University Press.

Lord, E. (2018). The importance of being rational. Oxford University Press.

Faraci, D. (2020). We have no reason to think there are no reasons for affective attitudes. Mind, 129(513), $225-234$.

Maguire, B. (2018). There are no reasons for affective attitudes. Mind, 127(507), 779-805.

McHugh, C. (2014). Fitting belief. Proceedings of the Aristotelian Society, 141(2pt2), 167-187.

McHugh, C., \& Way, J. (2016). Fittingness-first. Ethics, 126(3), 575-606.

Milona, M. (2016). Taking the perceptual analogy seriously. Ethical Theory and Moral Practice, 19(4), 897-915.

Müller, J.M. (2014). Affect and Intentionality: On the Significance of Emotional Feeling. PhD Thesis, University of Manchester

Müller, J. M. (2017). How (not) to think of emotions as evaluative attitudes. Dialectica, 71(2), 281-308.

Müller, J.M. (2019). The World-Directedness of Emotional Feeling: On Affect and Intentionality. Palgrave Macmillan

Müller, J. M. (2020). Response-dependent normative properties and the epistemic account of emotion. Journal of Value Inquiry, 54, 355-364.

Mulligan, K. (2010). Emotions and values. In T. Oxford (Ed.), Goldie, P (pp. 475-500). Oxford University Press.

Na'Aman, O. (forthcoming). Emotions and process rationality. Australasian Journal of Philosophy.

Naar, H. (forthcoming). Emotion: More like action than perception. Erkenntnis.

Naar, H. (ms.). Skepticism about reasons for emotions.

Nussbaum, M. (2001). Upheavals of thought. Cambridge University Press.

Orsi, F. (2015). Value theory. Bloomsbury.

Pelser, A. C. (2014). Emotion, evaluative perception, and epistemic justification. In C. Todd (Ed.), Roeser, $S$ (pp. 107-123). Oxford University Press.

Roberts, R. C. (2013). Emotions in the moral life. Cambridge University Press.

Ross, W. D. (1939). Foundations of ethics. Clarendon Press.

Rosen, G. (2015). The alethic conception of moral responsibility. In R. Clarke, M. McKenna, \& A. M. Smith (Eds.), The nature of moral responsibility: New essays. Oxford University Press, 65-88

Rowland, R. (2019). The Normative and the Evaluative: The Buck-Passing Account of Value. Oxford University Press

Scanlon, T. M. (1998). What We Owe to Each Other. Harvard University Press.

Schroeder, M. (2008). Having Reasons. Philosophical Studies, 139, 57-71.

Sharadin, N. (2016). Reasons Right and Wrong. Pacific Philosophical Quarterly, 97, 371-399.

Solomon, R. C. (2003). Not Passion's Slave. Oxford University Press. 
Tappolet, C. (2011). "Value and Emotions: Neo-Sentimentalism’s Prospects", in Bagnoli, C. (ed.), Morality and the Emotions, Oxford University Press

Tappolet, C. (2016). Emotions, Values, and Agency. Oxford University Press.

Publisher's Note Springer Nature remains neutral with regard to jurisdictional claims in published maps and institutional affiliations. 